\title{
Políticas do conhecimento e suas distintas narrativas
}

Fabrício Monteiro Neves, Joaze Bernardino-Costa \& Luís Augusto Sarmento Cavalcanti de Gusmão*

A s ciências sociais no Brasil, particularmente a sociologia, alcançaram uma complexidade de abordagens, métodos e temas que refletem bem os desafios que a sociedade mundial tem colocado à disciplina e, em específico, suas expressões entre nós. Neste número da Sociedade \& Estado três temas se destacam com mais força, articulando-se: ciência, políticas públicas e mundo rural. Estes temas se relacionam em quatro dos oito artigos originais desta edição, os quais nos oferecem distintas abordagens para compreender como o conhecimento científico influencia a política e a tomada de decisão no âmbito do Estado. O número ainda traz um diálogo entre as teorias da decolonialidade, a tradição do Atlântico Negro e a produção de intelectuais negros brasileiros, a história do Instituto de Pesquisa Econômica Aplicada (Ipea), desigualdade de gênero e divisão sexual do trabaIho no uso do tempo para trabalho no Brasil, percurso histórico da extensão universitária no Brasil e, finalizando a sessão de artigos, texto sobre o envelhecimento em Portugal e as redes informais de suporte. Trazemos também uma entrevista sobre métodos quantitativos com dois renomados pesquisadores da área e, na seção "Aulas Inaugurais", publicamos o texto escrito pela professora do Departamento de Sociologia Maria Stella Grossi Porto em função da cerimônia que Ihe outorgou o título de professora emérita da Universidade de Brasília. Encerramos com a tradicional sessão de resenhas.

Abre esta edição a discussão sobre ciência, tecnologia e sociedade, oferecida por Mariana Gameiro e Rodrigo Martins, no artigo "O desenvolvimento rural sob regime de verdade: o discurso do Banco Mundial". Pode-se ver no texto, como o banco disputa cognitivamente a definição das categorias legítimas de classificação do desenvolvimento rural em escala internacional, lançando mão não só de seu poder financeiro, mas, fundamentalmente, da autoridade concernente ao discurso científico. As definições alcançadas são importantes elementos nas políticas públicas defendidas pela instituição. Autora e autor articulam ainda na interpretação do discurso do Banco Mundial no campo das lutas cognitivas, o conceito de espaço de fluxos formulado por Manuel Castells, e análises de Michel Foucault acerca da construção de regimes de verdade.
* Professores do Departamento de Sociologia da Universidade de Brasília (UnB), Brasília (DF), Brasil. 
Novamente temos o tema ciência, tecnologia e sociedade - e mundo rural - nesta edição, agora na discussão dos usos sociais da ciência no caso da formulação de políticas públicas. Maria José Carneiro e Laila Sandroni, no texto em questão "Ciência e política pública na perspectiva dos gestores: clivagens e confluências" -, buscam, a partir dos dados gerados junto a gestores públicos, discutir a articulação entre ciência e políticas públicas, em específico aquelas relativas à agricultura familiar e conservação da biodiversidade. Importante ressaltar que o trabalho é desenvolvido à luz da perspectiva da "coprodução" entre ciência, Estado e cultura. O artigo é encerrado com reflexões sobre os limites e as possibilidades da contribuição do conhecimento científico às políticas públicas em um Estado democrático de direito.

O desenvolvimento rural e as políticas públicas também são temas do artigo "Políticas públicas para os assentamentos rurais e cooperativismo: entre o idealizado e as práticas possíveis", de autoria de Thainara Granero de Melo e Rosemeire Scopinho. No texto, fruto de estudo de caso realizado em uma cooperativa de um assentamento rural, localizada em Ribeirão Preto (SP), as autoras refletem sobre a distância entre a concepção de desenvolvimento rural das políticas públicas para assentamentos rurais e a realidade dos trabalhadores assentados cooperativados. Essa distância é acessada por meio do processo de institucionalização do cooperativismo, que leva em conta somente os dispositivos legais, desconsiderando condições objetivas e subjetivas dos trabalhadores na garantia da organização das redes de sustentação política e cultural necessárias ao funcionamento dessas instituições.

Everton Lazzaretti Picolotto nos traz em seu artigo "Pluralismo, neocorporativismo e o sindicalismo dos agricultores familiares no Brasil" uma discussão interessante a respeito do processo de formação da Federação dos Trabalhadores na Agricultura Familiar (Fetraf), em um contexto sindical desde a década de 1960 controlado pela Confederação Nacional dos Trabalhadores na Agricultura (Contag). Novamente, o tema é o novo mundo rural e sua expressão no sindicalismo. Segundo Picolotto, a estrutura sindical dos trabalhadores rurais existente até a criação da Fetraf não foi capaz de representar satisfatoriamente a diversidade de interesses e de grupos sociopolíticos que emergiram nos anos 1980 e 1990 no Brasil. A partir de então, tais grupos passaram a questionar a forma corporativa de representação, optando por constituir movimentos relativamente independentes dos canais sindicais tradicionais.

Joaze Bernardino-Costa propõe no artigo "Decolonialidade, Atlântico Negro e intelectuais negros brasileiros: em busca de um diálogo horizontal" uma articulação entre as teorias da decolonialidade, a tradição do Atlântico Negro e a produção 
de intelectuais negros brasileiros, chamando a atenção para o risco de um duplo apagamento da tradição desses intelectuais no Brasil, seja nas contribuições dos teóricos da decolonialidade, seja nos estudos sobre o Atlântico Negro. Contra este risco, Bernardino-Costa radicaliza a tese da corpo-geopolítica do conhecimento, presente no coração do projeto decolonial, e enfatiza a importância das raízes (roots) nos estudos do Atlântico Negro, dialogando com uma noção de intelectual orgânico de Antonio Gramsci e Anthony Bogues.

No artigo "Transformação institucional e produção de conhecimento aplicado: a história do Ipea social", Márcia Pereira Cunha nos apresenta a evolução do Instituto de Pesquisa Econômica Aplicada (Ipea), tendo como foco sua área de políticas sociais. A autora propõe apresentar esta história institucional por meio da evolução das formas de compreensão e das políticas dedicadas aos problemas sociais, complementando a periodização consolidada pela própria instituição, baseada em estágios de força, crise e recuperação institucionais. Ao fim, nos é oferecido um quadro rico do campo das políticas e suas conformações sociais no instituto.

O texto de Marcelo Medeiros e Luana Simões Pinheiro traz o tema da desigualdade de gênero e divisão sexual do trabalho no uso do tempo para trabalho no Brasil, baseando-se em dados da Pnad 2013. No texto, "Desigualdades de gênero em tempo de trabalho pago e não pago no Brasil, 2013", autor e autora mostram como o uso do tempo para trabalho é uma questão-chave para se entender o funcionamento da sociedade e os determinantes das desigualdades. Apresentam como a maior parte da desigualdade dentro do grupo de homens e de mulheres está associada à polarização entre trabalhar ou não. No estudo, dividem o tempo total de trabalho em tempo de trabalho pago e tempo de trabalho não pago - trabalho doméstico. Assim, conseguem mensurar a carga de cada tipo de trabalho e o grau de desigualdade dessa carga entre mulheres e homens e dentro desses grupos.

Extensão universitária é o tema do texto "O fortalecimento da extensão no campo científico: uma análise dos editais ProExt/MEC", de autoria de Lígia Incrocci e Thales Andrade. Além de contextualizar historicamente os percursos da extensão universitária no Brasil, desde seu surgimento na década de 1930 até o ano de 2016, autora e autor, utilizando-se dos resultados dos editais ProExt/MEC, observam a distribuição desigual dos recursos entre as linhas de pesquisa, as regiões do país e os tipos de instituições, bem como o crescimento e declínio do montante destinado. O processo de regulamentação da extensão, como indicado no artigo, possibilitou a esta se consolidar, adquirir reconhecimento e, consequentemente, ampliar seu espaço no interior das instituições de ensino superior, contra um histórico de falta de reconhecimento e recursos. 
Ainda na sessão de artigos, finalizamos com o tema do envelhecimento em Portugal e as redes informais de suporte. Sónia Guadalupe e Júlia Cardoso abordam a vulnerabilidade da população idosa, caracterizada pela perda de autonomia com o avançar da idade, o risco de isolamento social e o elevado risco de exclusão e de pobreza. No artigo, "As redes de suporte social informal como fontes de provisão social em Portugal: o caso da população idosa", as autoras discutem a relevância do suporte social informal na proteção à população idosa, problematizando o papel providencial das famílias num contexto de políticas de austeridade. Neste cenário, apoiando-se em documentação e na literatura corrente sobre o tema em Portugal, Guadalupe e Cardoso argumentam que o suporte estatal aos idosos tem se restringido, aumentando exponencialmente o papel de suporte das famílias.

Nesta edição, retomamos também a publicação de entrevistas com pesquisadores que são referências em suas respectivas áreas. No caso aqui trazido, trata-se de entrevista com professores de diferentes gerações e abordagens - Nelson do Valle Silva e Jerônimo Muniz -, ambos da área de metodologia quantitativa em estudos sociais e políticos. A entrevista, realizada por Natasha Bachini e Tathiana Chicarino, discute questões como os softwares e a relação entre pesquisa qualitativa e quantitativa.

Trazemos também, na seção "Aulas inaugurais", testemunho da professora do Departamento de Sociologia Maria Stela Grossi Porto, apresentado na cerimônia que Ihe outorgou o título de professora emérita da Universidade de Brasília. No texto "Razões e emoções de um título emérito: tempo e representações sociais", a autora combina aspectos acadêmicos e afetivos de sua trajetória, marcada pelo comprometimento, rigor científico e interesse nas áreas de representações sociais e violência.

Como de praxe, a edição é finalizada com resenhas. A primeira, de Marcio Mattos, debruça-se sobre o livro Great american city: Chicago and the enduring neighborhood effect (GAC), do sociólogo Robert J. Sampson, um importante estudo sobre vizinhança e seu efeito na estrutura da vida social das cidades. Finalmente, Touring poverty, de Bianca Freire-Medeiros, é resenhado por Ana Clara Telles, que traz o tema do "turismo de pobreza", fenômeno de escala global conhecido no Brasil como os tours em favelas.

Obs. Na edição publicada no site da revista (http://periodicos.unb.br/index.php/estado/index) há ainda a tradicional seção de resumos das teses e dissertações defendidas no Programa de Pós-Graduação em Sociologia da Universidade de Brasília (PGSOL).

Boa leitura! 


\section{Referências}

BACHINI, Natasha; CHICARINO, Tathiana Senne. Os métodos quantitativos, por cientistas sociais brasileiros: entrevistas com Nelson do Valle Silva e Jerônimo Muniz. Sociedade e Estado, v. 33, n. 1, p. 253-282, Brasília, Jan.-Abr. 2018.

BERNARDINO-COSTA, Joaze. Decolonialidade, Atlântico Negro e intelectuais negros brasileiros: em busca de um diálogo horizontal. Sociedade e Estado, v. 33, n. 1, p. 119-138, Brasília, Jan.-Abr. 2018.

CARNEIRO, Maria José Teixeira; SANDRONI, Laila Thomaz. Ciência e política pública na perspectiva dos gestores: clivagens e confluências. Sociedade e Estado, v. 33, n. 1, p. 41-62, Brasília, Jan.-Abr. 2018.

CUNHA, Márcia Pereira. Transformação institucional e produção de conhecimento aplicado: a história do Ipea social. Sociedade e Estado, v. 33, n. 1, p. 139-160, Brasília, Jan.-Abr. 2018.

GAMEIRO, Mariana Bombo Perozzi; MARTINS, Rodrigo Constante. O desenvolvimento rural sob regime de verdade: o discurso do Banco Mundial. Sociedade e Estado, v. 33, n. 1, p. 15-41, Brasília, Jan.-Abr. 2018.

GUADALUPE, Sónia; CARDOSO, Júlia. As redes de suporte social informal como fontes de provisão social em Portugal: o caso da população idosa. Sociedade e Estado, v. 33, n. 1, p. 215-250, Brasília, Jan.-Abr. 2018.

INCROCCl, Lígia Maria de Mendonça Chaves; ANDRADE, Thales Haddad Novaes de. O fortalecimento da extensão no campo científico: uma análise dos editais ProExt/ MEC. Sociedade e Estado, v. 33, n. 1, p. 189-214, Brasília, Jan.-Abr. 2018.

MEDEIROS, Marcelo; PINHEIRO, Luana Simões. Desigualdades de gênero em tempo de trabalho pago e não pago no Brasil, 2013. Sociedade e Estado, v. 33, n. 1, p. 161-188, Brasília, Jan.-Abr. 2018.

MATTOS, Marcio. Efeitos vizinhança e eficácia coletiva: a relevância do contexto na explicação sociológica. Resenha: SAMPSON, Robert J. Great American City: Chicago and the enduring neighborhood effect. Chicago: University of Chicago Press, 2012. Sociedade e Estado, v. 33, n. 1, p. 295-306, Brasília, Jan.-Abr. 2018.

MELO, Thainara Granero de; SCOPINHO, Rosemeire Aparecida. Políticas públicas para os assentamentos rurais e cooperativismo: entre o idealizado e as práticas possíveis. Sociedade e Estado, v. 33, n. 1, p. 63-86, Brasília, Jan.-Abr. 2018. 
PICOLOTTO, Everton Lazzaretti. Pluralismo, neocorporativismo e o sindicalismo dos agricultores familiares no Brasil. Sociedade e Estado, v. 33, n. 1, p. 87-118, Brasília, Jan.-Abr. 2018.

TELLES, Ana Clara. Turismo e pobreza na Era da "favela global". Resenha: BIANCA, Freire-Medeiros, Touring poverty. London: Routledge, 2013. Sociedade e Estado, v. 33, n. 1, p. 307-308, Brasília, Jan.-Abr. 2018. 